\title{
Prevalência de tuberculose no rebanho bovino de Mossoró, Rio Grande do Norte
}

Iza Alencar Sampaio de OLIVEIRA ${ }^{1}$

Hudson Paulinelly da

Câmara MELO'

Adaucides CÂMARA ${ }^{1}$

Regina Valéria da Cunha

DIAS $^{1}$

Benito SOTO-BLANCO ${ }^{1}$

\section{Correspondência para:}

UFERSA - BR 110 Km 47 - 59625-900,

Mossoró, RN soto-blanco@ufersa.edu.br,

bsotoblanco@yahoo.com.br

Recebido para publicação: 28/02/2005 Aprovado para publicação: 23/08/2007

\author{
1 - Departamento de Ciências Animais da Universidade Federal Rural do \\ Semi-árido, Mossoró - RN
}

\section{Resumo}

A tuberculose bovina é uma doença infecciosa crônica e debilitante que pode infectar humanos. Uma importante etapa para o controle é a determinação da prevalência nos rebanhos. O objetivo do presente trabalho foi determinar a prevalência da tuberculose bovina em Mossoró, RN. Inicialmente foi realizada uma avaliação de risco para a ocorrência da tuberculose bovina em 21 propriedades da região avaliada. Foram testadas 150 vacas leiteiras por meio do teste da prega caudal. Também foram avaliados outros 120 bovinos pelo teste da tuberculinização cervical comparada. Os resultados revelaram falta de conhecimento dos proprietários sobre o controle da doença, bem como o descuido no momento da aquisição de animais. A prevalência foi de $8,66 \%$ e 3,33\% nos testes da prega caudal e cervical comparativo, respectivamente. Assim, foi verificada uma prevalência de tuberculose bovina bastante elevada, sendo superior à média nacional.

\section{Introdução}

A tuberculose é uma doença infectocontagiosa, crônica, granulomatosa, caracterizada por formações específicas denominadas granulomas. Trata-se de uma doença antiga, disseminada pelo mundo inteiro e extremamente importante sob o ponto de vista de saúde pública, principalmente nos animais portadores da tuberculose mamária. O agente etiológico da tuberculose bovina é o Mycobacterium bovis, pertencente ao gênero Mycobacterium, como as espécies $M$. tuberculosis e $M$. avium, entre outras micobactérias. ${ }^{1}$ A tuberculose bovina é considerada uma zoonose pois pode ser transmitida ao homem. . $^{2,3}$

Os animais afetados geralmente são assintomáticos ou podem apresentar sintomas característicos como emagrecimento progressivo, tosse, dispnéia, aumento de linfonodos, redução na produção, entre outros. O método de diagnóstico mais utilizado para a detecção de animais tuberculosos é a prova da tuberculina, que pode ser realizada de três formas: pelo teste simples cervical, o cervical comparativo ou o da prega caudal. Devido à falta de aparelhagem adequada dos profissionais e por ser menos trabalhoso e oneroso, este último vem sendo o mais usado na triagem de rebanhos. ${ }^{4}$

No que se refere às perdas econômicas determinadas por esta enfermidade, estas se manifestam pela redução de 10 a $20 \%$ da produção de leite e do ganho de peso, infertilidade e na condenação de carcaças. Os principais fatores que favorecem a transmissão desta doença no rebanho são o contato aproximado entre os animais, principalmente leiteiros, criados semi-intensivamente ou em confinamento; presença de um animal portador, fonte constante de disseminação do agente no ambiente; e resistência deste agente às condições ambientais favoráveis. ${ }^{5}$

Segundo dados de $1986^{6}$, o nível de infecção pela tuberculose no rebanho bovino brasileiro variou entre 0,9 a 2,9\%. Neste sentido, o governo brasileiro, por meio do Ministério Agricultura, Pecuária e Abastecimento, Departamento de Defesa Animal, criou, em 2001, o Programa Nacional de Controle e Erradicação da 
Brucelose e Tuberculose Animal (PNCEBT), com os objetivos de reduzir o risco à saúde pública e promover o incremento $\mathrm{da}$ competitividade da pecuária nacional. ${ }^{5}$

Um trabalho epidemiológico a respeito da tuberculose bovina, realizado no Rio Grande do Norte, apontou a impressionante incidência de $43,9 \%{ }^{7}$, valor este que provavelmente está superior à realidade da bovinocultura norte-riograndense. Assim, este trabalho tem como objetivo fazer um levantamento de possíveis casos positivos e assim alertar as autoridades para a extensão do problema e ajudar na tomada de medidas de controle da doença.

\section{Material e Método}

Levantamento de fatores de risco da tuberculose bovina em Mossoró, RN

Mossoró, município da região oeste do Rio Grande do Norte, possui uma área de $2.110 .207 \mathrm{~km}^{2}$, população de 205.822 habitantes, rebanho bovino é estimado em 20.950 animais e produção anual de leite de 4.329 mil litros, segundo dados de 2002. A micro-região de Mossoró inclui também os municípios de Areia Branca, Baraúna, Grossos, Serra do Mel e Tibau, com rebanho bovino de 35.964 animais e produção anual de 5.088 mil litros de leite, também relativo a 2002 .

Em 21 propriedades do município de Mossoró, foi aplicado um questionário sobre as seguintes informações: rebanho total da propriedade, quantidade de leite produzida, aquisição dos animais, freqüência de realização do teste tuberculínico no rebanho, presença de animais suspeitos, destino do leite e consumo do mesmo na propriedade de origem, e reconhecimento da tuberculose bovina como zoonose.

\section{Teste da prega caudal}

Foram testadas 150 vacas leiteiras procedentes do município de Mossoró, mestiças ou puras de origem européia, com idade superior a cinco anos e que estavam em lactação. O teste da prega caudal foi realizado por meio da aplicação intradérmica de $0,1 \mathrm{ml}$ de tuberculina PPD bovina (cepa AN5, origem Roterdã) de potência e especificidade adequada, segundo requisitos internacionais e regionais de controle de qualidade, produzida pelo laboratório Tecpar, com número de partida de 001/03. Feita a assepsia do local com algodão embebido com álcool $70 \%$, a tuberculina foi aplicada na porção média da prega anocaudal direita do bovino, com observação dos resultados após 72 horas da aplicação.

O diagnóstico foi feito pela inspeção e palpação do local, presença de aumento de espessura e textura da pele e edema no ponto de inoculação, comparando sempre com o lado oposto da prega ano-caudal testada. As reações positivas foram identificadas pela presença de reação local ou por tumefação difusa da prega inoculada.

Teste da tuberculinização comparada cervical

Foram utilizados 120 bovinos adultos, oriundos de 15 diferentes propriedades, localizadas na Região Oeste do RN, compreendendo os municípios de Mossoró, Governador Dix-Sept-Rosado, Umarizal e Baraúnas. Estas propriedades se caracterizam por pequeno porte com produção escoada ao mercado consumidor como leite in natura para consumo da população local dos municípios avaliados.

Os animais foram submetidos ao teste da tuberculina. O teste utilizado no desenvolvimento deste trabalho foi a tuberculinização comparada cervical, com as tuberculinas bovina e aviária, pois segundo o Departamento de Defesa Animal do Ministério da Agricultura ${ }^{5}$ é o único teste que, além de poder ser utilizado para a triagem em todas as raças, também é considerado confirmatório para esta enfermidade, com especificidade de pelo menos $99 \%$. O teste tuberculínico cervical comparado foi realizado por meio de injeção intradérmica pareada de $0,1 \mathrm{ml}$ de tuberculina PPD bovina e aviária, de potências e especificidades adequadas, segundo requisitos internacionais e regionais de controle de qualidade, produzidas pelo laboratório Tecpar, com 
número de partida de 002/04. A tuberculina foi aplicada na porção média da tábua do pescoço do bovino, após assepsia com álcool a $70 \%$, com observação dos resultados após 72 horas da aplicação. A interpretação dos resultados foi realizada segundo o DDA. ${ }^{5}$

\section{Resultados e Discussão}

Nas vinte e uma propriedades, foi encontrado um rebanho de 1.009 cabeças, com a produção leiteira total de 1.985 litros de leite por dia, sendo 287 vacas com idade superior a cinco anos. O leite produzido é escoado para o consumo in natura pela comunidade mossoroense. $\mathrm{Na}$ pesquisa sobre o reconhecimento da tuberculose como um zoonose passível de transmissão pelo leite, $80,95 \%$ dos entrevistados afirmaram estar conscientes, existindo ainda uma parcela que desconhece este fato. De fato, já foi isolado M. bovis do leite, manteiga, creme, queijo fresco e queijo integral curado. ${ }^{8}$ A contaminação pela tuberculose bovina por comunidades urbanas e rurais não profissionais ocorre principalmente por meio da ingestão do leite e derivados não pasteurizados ou fervidos, e entre profissionais também pelo contato direto com lesões tuberculosas e infecções de estábulos. ${ }^{9}$ Os dados sobre o consumo de leite na própria propriedade revelaram que poucos entrevistados o consumo do leite in natura, enfatizando que o mesmo era sempre fervido, bem como o leite utilizado para a produção de coalhada. Este dado é indício de uma relativa preocupação em relação ao consumo do leite e uma conscientização sobre os riscos que possa trazer à saúde humana.

O Ministério da Agricultura do Brasil, em consenso com os padrões internacionais e com as recomendações do Código Zoosanitário Internacional, recomenda o teste cervical simples para fins de triagem simples do rebanho, e o comparado cervical como a única prova confirmatória. Por outro lado, o teste da prega caudal deve ser utilizado apenas para animais de corte, como teste de triagem do rebanho. ${ }^{5}$ No entanto, Mota e Lobato ${ }^{10}$ afirmavam que a tuberculinização podia ser feita na prega caudal quando não se dispusesse de instrumental necessário para a execução do teste no pescoço ou na escápula, sendo ainda que o método era o mais empregado no Brasil na época, porque a maioria dos profissionais não possuía instrumental adequado para o teste na região cervical. ${ }^{10}$ As principais vantagens do teste da prega caudal são a alta sensibilidade, similar ao teste simples cervical, e também a alta especificidade, facilidade e rapidez de aplicação e leitura, servindo apropriadamente para fins de triagem do rebanho. ${ }^{1}$

Considerando o total de 150 animais submetidos ao teste de tuberculina pelo teste da prega caudal (Tabela 1), 13 animais foram reagentes, ocorrendo, assim, prevalência de $8,66 \%(13 / 150)$ de animais positivos, com nível de infecção de 47,62\% (10/21) nas propriedades visitadas.

A prova de tuberculinização comparada (Tabela 2) revelou 3,33\% (4/120) bovinos positivos e inconclusivos, sendo $0 \%$ em Umarizal, $0 \%$ em Baraúnas, $0 \%$ em Governador Dix-Sept Rosado e 6,66\% (4/ 60) em Mossoró, com apenas um caso inconclusivo e 116 negativos. O nível de infecção por localidade visitada foi de 14,28\% (2/14). A freqüência de bovinos taurinos e zebuínos foi de $87 \%$ e $13 \%$, respectivamente. Nenhum dos animais de origem zebuína testados obteve reação no teste tuberculínico, o que provavelmente está relacionado à menor susceptibilidade destes em contraírem a tuberculose, quando comparados aos bovinos de origem européia. ${ }^{8}$

Langenegger, Langenegger e Oliveira $^{7}$ relataram que o Rio Grande do Norte apresenta uma incidência de 43,9\% de bovinos com tuberculose, segundo resultados obtidos pela prova cervical simples com tuberculina bovina. Por outro lado, no presente estudo foi detectada a presença de 8,66\% pelo teste de tuberculinização da prega caudal e 3,33\% no teste cervical comparativo, que são bastante inferiores ao valor relatado 
Tabela 1 - Resultados da tuberculinização de bovinos da região de Mossoró, RN, pelo Teste da Prega Caudal

\begin{tabular}{lccc}
\hline Grupo de animais & Animais Testados & Reagentes & Não-Reagentes \\
\hline Todos & 150 & $13(8,66 \%)$ & $137(91,3 \%)$ \\
Origem racial & 139 & $12(8,63 \%)$ & $127(91,4 \%)$ \\
Mestiços & 11 & $1(9,09 \%)$ & $10(90,9 \%)$ \\
Raça pura européia & & & $65(98,5 \%)$ \\
Localidade & 66 & $1(1,52 \%)$ & $29(82,3 \%)$ \\
Pintos & 35 & $6(17,7 \%)$ & $7(70 \%)$ \\
Bom Jesus & 10 & $3(30 \%)$ & $15(100 \%)$ \\
Rincão & 15 & 0 & $6(75 \%)$ \\
Espinheirinho & 8 & $2(25 \%)$ & $6(100 \%)$ \\
Sumaré & 6 & 0 & $9(90 \%)$ \\
Barrocas & 10 & $1(10 \%)$ & \\
RN-117 & & &
\end{tabular}

Tabela 2 - Resultados da tuberculinização de bovinos da região de Mossoró, RN, pelo Teste Cervical Comparativo

\begin{tabular}{lccc}
\hline \multicolumn{1}{c}{ Grupo de animais } & Animais Testados & Reagentes & Não-Reagentes \\
\hline Todos & 120 & $4(3,33 \%)$ & $116(96,7 \%)$ \\
Origem racial & 104 & $4(3,85 \%)$ & $100(96,2 \%)$ \\
Taurinos & 16 & 0 & $16(100 \%)$ \\
Zebuínos & 5 & $2(40 \%)$ & $3(60 \%)$ \\
Localidade & 5 & 0 & $5(100 \%)$ \\
Alto da Conceição & 10 & 0 & $10(100 \%)$ \\
Alto do Sumaré & 8 & 0 & $8(100 \%)$ \\
Baraúna & 28 & 0 & $28(100 \%)$ \\
Bom Jesus & 13 & $2(15,4 \%)$ & $11(84,6 \%)$ \\
Costa e Silva & 50 & 0 & 50 \\
Pintos & & & 5 \\
Umarizal & 5 & &
\end{tabular}

anteriormente. No entanto, estes dados mostram que a incidência da tuberculose está superior à média nacional, que foi estimada em 1,3\% entre 1989 e $1998 .^{11}$ Desta forma, a região oeste do $\mathrm{RN}$ caracteriza-se como uma área de risco epidemiológico para esta enfermidade, precisando da intensificação de testes e da fiscalização pecuária em todas as propriedades.

Alguns fatores que podem ter contribuído para a elevada prevalência de tuberculose bovina em Mossoró são a falta 
de conscientização dos proprietários sobre os riscos que a tuberculose bovina pode trazer aos animais e à comunidade que consome o leite in natura, e a falta de cuidado na introdução de novos animais ao rebanho, não sendo exigido atestado negativo de tuberculose no momento da compra. De fato, a aquisição de animais infectados é considerada a principal forma de introdução da tuberculose no rebanho. ${ }^{11,12}$ Ainda, as condições de manejo observadas na maioria das propriedades visitadas, bem como as instalações, eram inadequadas e a criação era semi-intensiva, favorecendo o contato freqüente entre os animais. Segundo Mota e Lobato $^{10}$, estes são fatores que também contribuem para a disseminação da doença no rebanho.

Assim, fica evidente que a região oeste potiguar necessita de uma atenção especial, na realização de um trabalho em várias frentes, desde a conscientização do produtor, passando pela fiscalização nas barreiras sanitárias, até levantamentos periódicos da situação epidemiológica desta doença na região avaliada. Além disto, há o agravante que o leite obtido dos animais da região em grande parte é comercializado no mercado informal, sem qualquer processamento térmico, produzindo risco direto à população que consuma o leite in natura.

\title{
A survey of tuberculosis in the cattle from Mossoro, Rio Grande do Norte State
}

\begin{abstract}
Bovine tuberculosis is an infectious chronic and debilitating disease that can infect humans. A key step for its controls is to determine the prevalence in the herd. The present study aimed to determine the prevalence of bovine tuberculosis at Mossoró, RN. Initially, it was done an evaluation for infection hazard by tuberculosis in bovines at 21 farms. It were tested 150 dairy cows by caudal-fold tuberculin test. Other 120 bovines were also tested by comparative cervical tuberculin test. The results revealed lack of knowledge by owners about the prevention of the disease, as well as negligence when they buy animals. The prevalence was $8.66 \%$ at the cervical test and $3.33 \%$ at caudal-fold tuberculin test and comparative cervical tuberculin test, respectively. Thus, it was verified a high prevalence of bovine tuberculosis, which is greater than the national mean prevalence.
\end{abstract}

\section{Referências}

1 ROXO, E. Tuberculose bovina: revisão. Arquivos do Instituto Biológico, v. 63, p. 91-97, 1996.

2 KLEEBERG, H. H. Human tuberculosis of bovine origin in relation to public health. Revue Scientifique et Technique OIE, v. 3, p. 1-32, 1984.

3 RIEDER, H. L. Bases epidemiológicas do controlo da tuberculose. Lisboa: Direção-Geral da Saúde, 2001. $168 \mathrm{p}$.

4 RADOSTITS, O. M.; GAY, C. C.; BLOOD, D. C.; HINCHCLIFF, K. W. Clínica veterinária. 9 ed. São Paulo: Guanabara- Koogan, 2002. 1737 p.

5 BRASIL. Ministério da Agricultura. Departamento de Defesa Animal (DDA). Programa Nacional de Controle
Key Words:

Bovine. Zoonoses. Mycobacterium bovis. Tuberculin. e Erradicação da Brucelose e Tuberculose (PNCEBT). Brasília: Ministério da Agricultura, 2003.

6 KANTOR, I. N.; RITACCO, V. Bovine tuberculosis in Latin America and Caribbean: current status, control and erradication programs. Veterinary Microbiology, v. 40, p. 5-14, 1994.

7 LANGENEGGER, J.; LANGENEGGER, C. H.; OLIVEIRA, J. D. Tratamento massal da tuberculose bovina com isoniazida. Pesquisa Veterinária Brasileira, v. 11, n. 1, p. 21-23, 1991.

8 CORRÊA, W. M.; CORRÊA, C. N. M. Enfermidades infecciosas dos mamíferos domésticos. 2 ed. São Paulo: Medsi, 1992. 843 p.

9 BUBNIAK, F. Diagnóstico epidemiológico da tuberculose na espécie bovina no Estado de Santa Catarina, 2000. 63 f. Monografia (Especialização em 
Sanidade Animal) - Centro de Ciências Agrárias, Lages, 2000.

10 MOTA, P. M. P. C.; LOBATO, F. C. F. Tuberculose bovina: uma revisão. In: LAGE, A. P.; LOBATO, F. C. F.; MOTA, P. M. P. C.; GONÇALVES, V. S. P. Atualização em tuberculose bovina. Belo Horizonte: PEP-MVZ, 1998. p. 3-34.

11 BELCHIOR, A. P. C. Prevalência, distribuição regional e fatores de risco da tuberculose bovina em Minas Gerais. 2001. 55 f. Dissertação (Mestrado em Medicina Veterinária Preventiva e Epidemiologia) - Escola de Veterinária, Universidade Federal de Minas Gerais, Belo Horizonte, 2001.

12 RIBEIRO, A. R. P. et al. Prevalência de tuberculose e brucelose bovina no município de Ilhéus. Arquivo Brasileiro de Medicina Veterinária e Zootecnia, v. 55, n. 1, p. 120-122, 2003. 